\title{
Sexually dimorphic influence of the circadian clock gene Bmal1 in the striatum on alcohol intake
}

\author{
Nuria de Zavalia, Konrad Schoettner, Jory A. Goldsmith, Pavel Solis, Sarah Ferraro, Gabrielle
} Parent, and Shimon Amir*

Center for Studies in Behavioral Neurobiology

Department of Psychology

Concordia University

Canada

* Correspondence: shimon.amir@concordia.ca

\section{Summary}

The gene Bmall (brain and muscle Arnt-like 1) plays an obligatory role in the generation of circadian rhythms in the suprachiasmatic nucleus (SCN), the master circadian clock in mammals [1-5]. Notably, Bmall is widely expressed in mammalian brain [6], and perturbations in Bmall expression in select forebrain regions cause behavioral disturbances that are independent of the $\mathrm{SCN}$, such as disturbances in sleep architecture, and in cognitive and affective behaviors [1, 7-15]. Interestingly, gene association studies in humans and in animals suggest that Bmall may influence the propensity to consume alcohol, and that polymorphisms in Bmall may confer risk for alcohol dependence and related disorders [16-20]. However, research has not yet provided evidence of a causal role of Bmall in the control of alcohol intake. We investigated voluntary alcohol consumption in conditional knockout mice that lack Bmall exclusively in the striatum, which is an important structure in the control of alcohol intake and preference [21-26]. Experiments were carried out in both male and female mice in order to account for the known sex differences in alcohol consumption [27-31] and in striatal functioning [32-36], as well as in the expression of clock genes and in the impact of circadian clocks on behavior [37-44]. We found that, in both males and females, selective deletion of Bmall from principal medium spiny neurons (MSNs) of the striatum significantly altered voluntary alcohol intake and preference. Strikingly, the effect of Bmall deletion was sexually dimorphic. Whereas in males, deletion of Bmall augmented alcohol intake and preference, in females, the same deletion suppressed alcohol intake and preference. Interestingly, striatal deletion of the clock gene Per2, which interacts with Bmall in the generation of circadian rhythms [4], and which has been shown to affect alcohol consumption in male mice [45], mimicked the effect of Bmall deletion, albeit only in males. These results show that Bmall in MSNs of the striatum exerts a sexually dimorphic influence on alcohol intake in mice, moderating intake in males, possibly via Per2, and promoting heightened intake in females, independently of Per 2 . We propose that a sexually dimorphic mechanism in the function of Bmall in the striatum contributes to sex differences in the propensity to consume alcohol in mice.

Whether such mechanism contributes to sex differences in other striatum-dependent appetitive and consummatory behaviors remains to be investigated.

Expression of BMAL1 in Striatal MSNs and Generation of Striatal Bmal1 Knockout Mice Striatal MSNs play an important role in alcohol neuroadaptation and alcohol intake and preference $[22,46-48]$. They constitute approximately $95 \%$ of the entire striatal neuronal population in mice 
$[49,50]$ and consist of two intermixed populations, one that projects directly (striatonigral), and one that projects indirectly (striatopallidal) to the output nuclei of the basal ganglia [51].

Striatonigral MSNs are distinguished by the expression of D1 dopamine (DA) receptors, and striatopallidal MSNs by the expression of D2 DA receptors [52]. Both MSNs subtypes express Gpr88, a striatum-specific G-protein coupled receptor [53-55]. Using fluorescence immunohistochemistry in tdTomato-D1/GFP-D2 double transgenic reporter mice [56], we confirmed that both D1 and D2 DA receptor bearing neurons in the striatum express BMAL1 (Figure 1A). Moreover, using transgenic mice that express Cre and green fluorescent protein (GFP) under control of the Gpr88 promoter, we confirmed that BMAL1 is expressed in Gpr88bearing neurons of the striatum (Figure 1B).

Figure 1. BMAL1 expression is dampened in MSNs of conditional Bmall knockout mice.

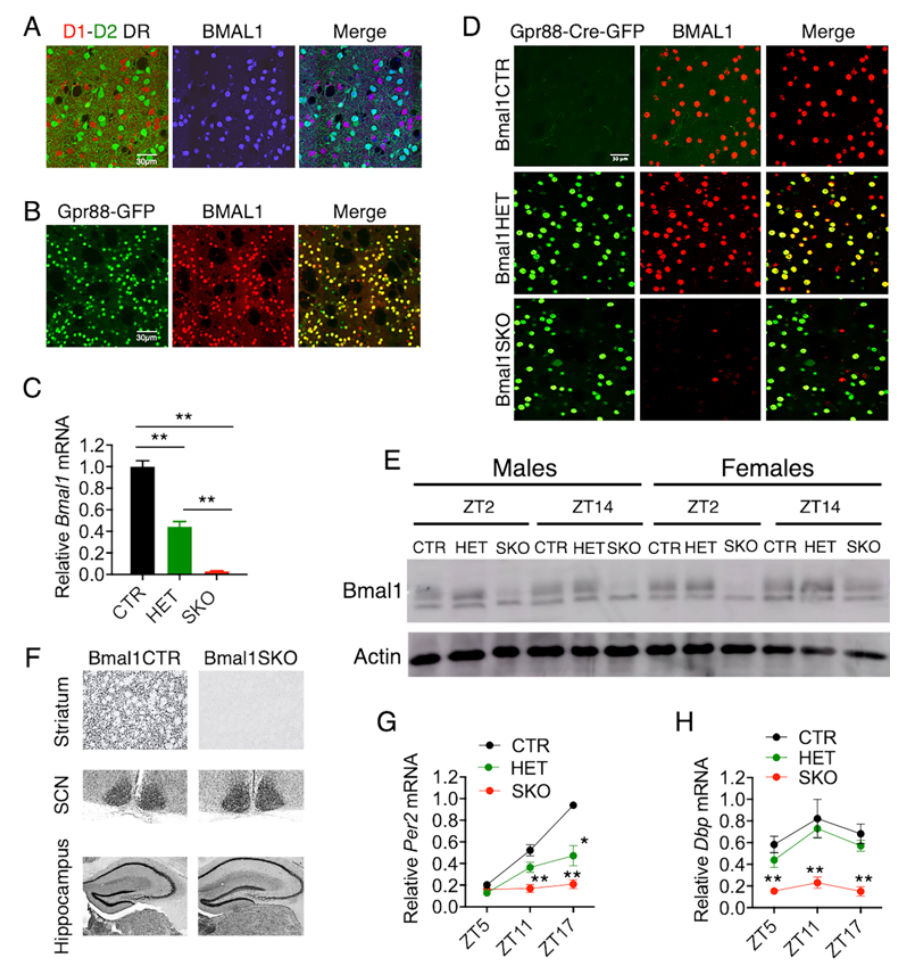

A) Representative images of immunofluorescence staining in tdTomato-D1/GFP-D2 double transgenic reporter mice showing that BMAL1 (blue) is expressed in D1 (red) and D2 (green) dopamine receptor bearing neurons of the dorsal striatum (scale bar $=30 \mu \mathrm{m})$.

B) Representative images of immunofluorescence staining showing that BMAL1 (red) is expressed in Gpr88-Cre-GFP (green) positive MSNs of the mouse dorsal striatum (scale bar $=30 \mu \mathrm{m}$ ).

C) Quantitative PCR analysis of dorsal striatal tissue shows a clear effect of gene dosage on Bmall mRNA levels, with Bmall knockout mice displaying almost no expression, and Bmall heterozygote mice exhibiting approximately half of the mRNA levels as control mice in the striatum. There were significant differences between all groups $(* * \mathrm{P}<0.0001$, unpaired two-tailed t test).

D) Representative image of immunofluorescence staining showing that Bmall knockout mice which express Cre-GFP in dorsal striatal MSNs, and have two floxed Bmall alleles, display depleted BMAL1 in GFP-positive cells. Bmall heterozygote mice which express Cre, but only possess a single floxed Bmall allele, retain BMAL1 expression. Control mice which contain two floxed Bmall alleles, but lack Cre, retain BMAL1 expression.

E) A representative western blot image confirming BMAL1 depletion in the dorsal striatum of SKO male and female mice at two different times of the day.

F) Representative image of immunohistochemistry staining showing expression of BMAL1 in the hippocampus and SCN, but not in the striatum of Bmall knockout mice.

G) Quantitative PCR analysis showing that Per 2 mRNA levels were downregulated and its rhythm was blunted across the light-dark cycle in the dorsal striatum of conditional Bmall knockout mice. $(* \mathrm{P}<0.01$, $* * \mathrm{P}<0.005$, unpaired twotailed t test).

H) Quantitative PCR analysis of Dbp mRNA expression shows a downregulation of this gene in the dorsal striatum of conditional Bmall knockout mice. (** represent significant difference from control, $\mathrm{p}<0.005$, unpaired two-tailed $\mathrm{t}$ test).

Mice with specific deletion of Bmall from MSNs of the striatum were generated using the Crelox recombination strategy. C57BJ/6 mice homozygous for floxed alleles of the Bmall locus ([Bmal1fl/fl], JAX, stock number 7668) were crossed with transgenic mice that express Cre recombinase and GFP under control of the Gpr88 promoter ([Gpr88Cre/+], JAX, stock number 22510) to yield striatal specific Bmall knockout mice (Gpr88Cre/+; Bmal1fl/fl [Bmal1SKO]), as well as heterozygotes (Gpr88Cre/+; Bmal1fl/+ [Bmal1HET]) and wild type controls (Gpr88+/+; 
Bmal1fl/fl [Bmal1CTR]). The resulting Bmal1SKO and Bmal1HET male and female mice were similar to their littermate controls in weight. Quantitative real-time polymerase chain reaction (qPCR) analysis of striatal tissue punches $(\mathrm{n}=3$ /genotype) revealed a significant reduction of mRNA levels within the floxed Bmall locus to less than 5\% of control levels in Bmal1SKO mice $(\mathrm{P}<0.0001$, unpaired two-tailed $\mathrm{t}$ test $)$ and less than $50 \%$ of control levels in Bmal1HET mice $(\mathrm{P}<0.0001$, unpaired two-tailed t test) (Figure 1C). Using fluorescence immunohistochemistry, we confirmed that striatal brain sections from Bmal1CTR and Bmal1HET mice expressed BMAL1, whereas striatal sections from Bmal1SKO mice lacked BMAL1 immunostaining (Figure 1D). The reduction of BMAL1 protein in the striatum was further confirmed by western blotting analysis of striatal tissue punches. In both male and female Bmal1SKO mice, the expression of BMAL1 was substantially lower at zeitgeber time (ZT) 2 and ZT14 compared to control animals (Figure 1E). Moreover, we confirmed that the deletion of Bmall is restricted to the striatum by showing presence of BMAL1 staining in the SCN and hippocampus of Bmal1SKO mice (Figure 1F). To determine whether deletion of Bmall disrupted the striatal circadian clock we studied the expression of the clock gene, Per2, which depends on Bmall for expression and daily cycling (n=3/timepoint). In Bmal1CTR mice, Per2 mRNA levels in the striatum peaked at night (ZT17). In contrast, in Bmal1SKO mice, the levels of Per $2 \mathrm{mRNA}$ were significantly downregulated at ZT11 (CTR versus SKO, P $<0.005$, unpaired two-tailed t test) and ZT17 ( $<<0.005$, unpaired twotailed $t$ test) and its rhythm was blunted across the light-dark cycle (Figure $1 \mathrm{G}$ ). In addition, the analysis of the mRNA expression of the canonical clock-controlled gene Dbp shows that Bmall deletion from MSNs induced a significant downregulation of this gene in the striatum (CTR versus $\mathrm{SKO}, \mathrm{P}<0.005$ for all timepoints, unpaired two-tailed t test) (Figure $1 \mathrm{H}$ ). These results suggest that both Per2 and Dbp expression in MSNs are controlled locally by Bmall and that in the absence of Bmall in the expression of these genes is disrupted.

\section{Sexually Dimorphic Effect of Bmal1 Deletion from MSNs on Alcohol Intake and Preference}

To study alcohol intake and preference, 12 - 18 weeks old male and female Bmal1CTR mice (males, $\mathrm{n}=12$; females, $\mathrm{n}=17$ ) and Bmal1SKO mice (males, $\mathrm{n}=13$; females, $\mathrm{n}=14$ ), were housed individually under a normal 12:12 h light-dark cycle, with food and water available ad libitum. For measurements of voluntary alcohol consumption, mice had free access to one bottle of $15 \%$ ethanol solution in tap water $(\mathrm{vl} / \mathrm{vl})$ and one bottle of only tap water, every other day, in alternate left-right position, for a total of 11 sessions. Analysis of variance (ANOVA) revealed a significant main effect of genotype on alcohol intake ( $\mathrm{g} / \mathrm{Kg} /$ day) and preference (alcohol intake/total fluid intake) in both males (Figures 2A and B) and females (Figures 2C and D). Specifically, Bmal1SKO males consumed significantly more alcohol ( $\mathrm{P}<0.002$, ANOVA) and

Figure 2. Opposite effects of striatal Bmall deletion on alcohol intake and preference in male and female mice

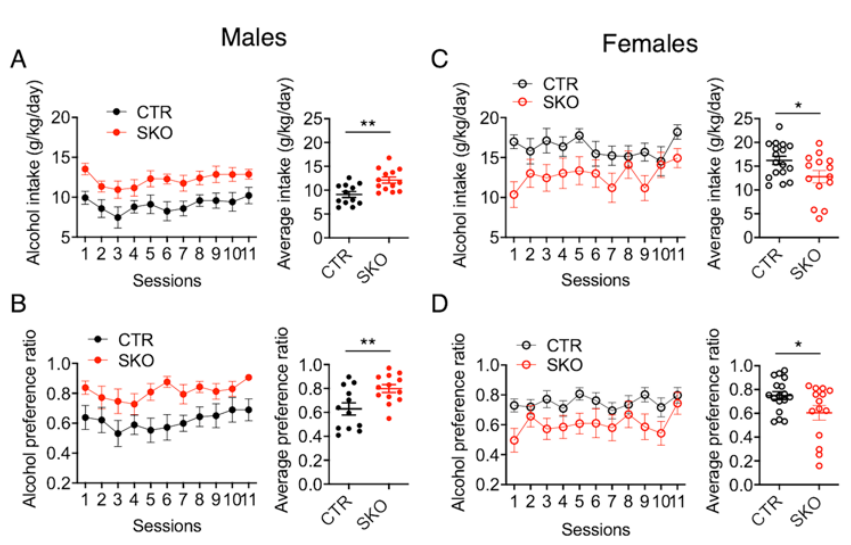

A) Mean \pm S.E.M. daily alcohol consumption (left) and average alcohol consumption (right) in control (CTR, $\mathrm{n}$ $=12)$ and Bmall knockout $(\mathrm{SKO}, \mathrm{n}=13)$ male mice (**P<0.01, unpaired two-tailed $t$ test).

B) Mean \pm S.E.M. daily alcohol preference (left) and average alcohol preference (right) in CTR and Bmall SKO male mice $(* * \mathrm{P}<0.01$, unpaired two-tailed $\mathrm{t}$ test). C) Mean \pm S.E.M. of daily alcohol intake (left) and average alcohol intake in CTR $(\mathrm{n}=17)$ and Bmal1 SKO $(\mathrm{n}=14)$ female mice $\left({ }^{*} \mathrm{P}<0.05\right.$, unpaired two-tailed $\mathrm{t}$ test).

D) Mean \pm S.E.M. of daily alcohol preference (left) and average preference in CTR and Bmal1 SKO female mice $(* * \mathrm{P}<0.05$, unpaired two-tailed t test). 
exhibited significantly greater alcohol preference $(\mathrm{P}<0.005$, ANOVA) than Bmal1CTR mice over the 11 alcohol test days. On average, the daily alcohol intake $(12.12 \pm 0.64 \mathrm{~g} / \mathrm{Kg})$ and preference $(0.80 \pm 0.03)$ of Bmal1SKO male mice were $33 \%$ and $36 \%$ higher, respectively, than those of Bmal1CTR mice (average intake, $9.1 \pm 0.62 \mathrm{~g} / \mathrm{Kg}$; average preference, $0.62 \pm 0.05$; unpaired twotailed t test, intake: $\mathrm{P}<0.003$; preference: $\mathrm{P}<0.005$, unpaired two-tailed t test). In contrast to males, Bmal1SKO females consumed significantly less alcohol than Bmal1CTR mice $(\mathrm{P}<0.03$, ANOVA) and exhibited lower alcohol preference $(\mathrm{P}<0.05$, ANOVA) over the 11 alcohol test days. The mean daily alcohol intake of Bmal1SKO females was $22 \%$ lower than that of Bmal1CTR females $(12.79 \pm 1.29$ versus $16.21 \pm 0.88 \mathrm{~g} / \mathrm{Kg}, \mathrm{P}<0.03$, unpaired two-tailed $\mathrm{t}$ test $)$. The mean daily alcohol preference value of Bmal1SKO females was $15 \%$ lower than that of Bmal1CTR females $(0.60 \pm 0.06$ versus $0.75 \pm 0.03, \mathrm{P}<0.03$, unpaired two-tailed $\mathrm{t}$ test $)$.

\section{Striatal Deletion of Per2 Mimicks the Effect of Bmal1 Deletion on Alcohol Intake in Males}

Bmal1 plays an obligatory role in transcriptional activation of the core clock gene Per2, and analysis of Per 2 mRNA in the striatum of Bmal1SKO and Bmal1HET mice revealed gene-dose dependent suppression of Per2 expression at ZT5 and 17 (Figure 1G). Per2 has been associated with alcohol consumption in humans, and global disruption of Per2 has been shown to augment alcohol intake and preference in male mice [45], raising the possibility that the effect of striatal Bmall deletion on alcohol intake and preference involves changes in local expression of Per 2 . MSNs that express D1 or D2 DA receptors and GPR88 also express PER2 (Figures 3A and 3B).

\section{Figure 3. Alcohol consumption is altered in Per2 knockout male mice}
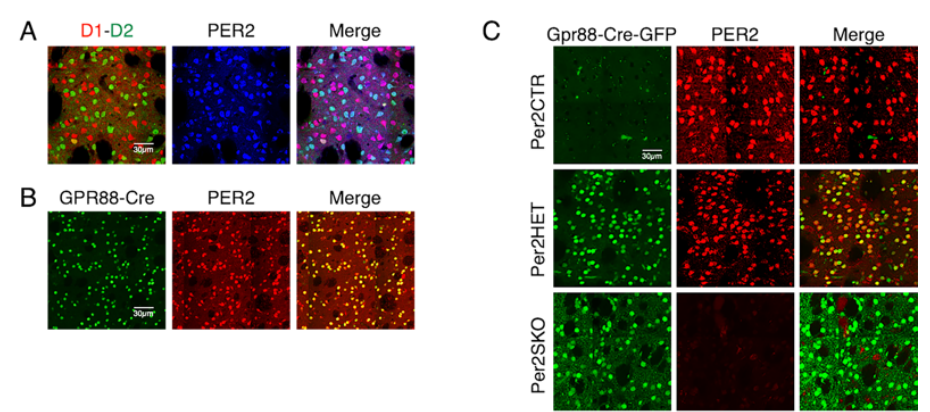

A) Representative image of immunofluorescence staining showing that PER2 (blue) is expressed in D1 (red) and D2 (green) dopamine receptor bearing neurons of the dorsal striatum in tdTomato-

D1/GFP-D2 double transgenic reporter mice (scale bar $=30 \mu \mathrm{m})$.

B) Representative image of immunofluorescence staining showing that PER2 (red) is expressed in Gpr88-Cre-GFP (green) positive MSN of the mouse dorsal striatum (scale bar $=30 \mu \mathrm{m})$.

C) Representative image of immunofluorescence
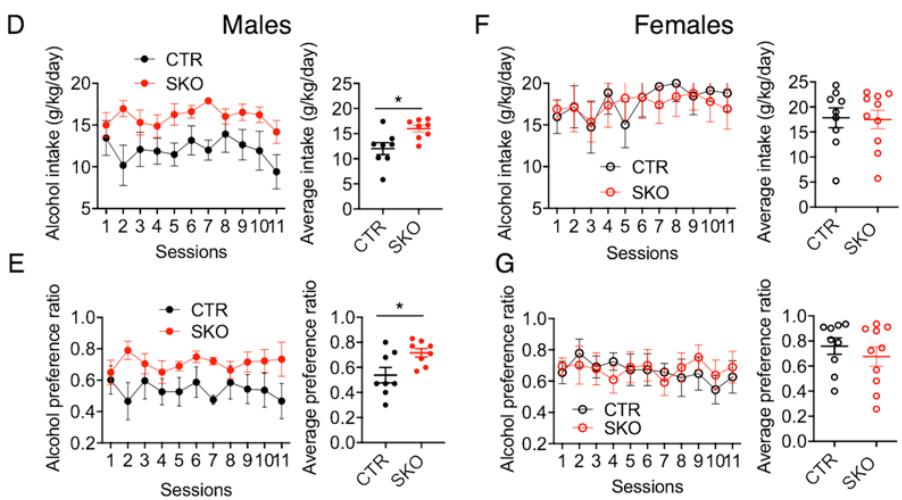
staining showing that Per 2 knockout mice which express Cre-GFP in dorsal striatal MSNs and have two floxed Per2 alleles, display depleted PER2 in GFP-positive cells. Per 2 heterozygote mice which express Cre, but only possess a single floxed Per 2 allele, retain PER2 expression. Control mice which contain two floxed Per2 alleles, but lack Cre, retain PER2 expression.

D) Mean \pm S.E.M. of daily alcohol consumption (left) and average alcohol consumption (right) in control (CTR, $\mathrm{n}=8)$ and Per2 knockout (SKO, $\mathrm{n}=$ 8) males $(* \mathrm{P}<0.05$, unpaired two-tailed t test $)$.

E) Mean \pm S.E.M. of daily alcohol preference (left) and average alcohol preference (right) in Per2CTR and Per2SKO male mice ( ${ }^{*} \mathrm{P}<0.05$, unpaired two-tailed t test). F) Mean \pm S.E.M of daily alcohol consumption (left) and average alcohol consumption (right) in Per2CTR $(n=9)$ and Per2SKO $(n=10)$ female mice.

G) Mean \pm S.E.M. of daily alcohol preference (left) and average alcohol preference (right) in Per2CTR and Per2SKO female mice.

To study the contribution of striatal Per2 gene expression, we crossed C57BJ/6 mice homozygous 
for floxed alleles of the Per2 locus (Per2fl/fl, European Mouse Mutant Archive, Strain ID: EM10599) with mice that express Cre and GFP under control of the Gpr88 promoter to generate Per2SKO (Gpr88Cre/+; Per2fl/fl), Per2HET (Gpr88Cre/+; Per2fl/+) and Per2CTR (Gpr88+/+; Per2fl/fl) male and female mice. Immunostaining of striatal brain sections from Per2SKO mice revealed complete absence of PER2 immunoreactivity (Figure 3C). Deletion of Per2 from MSNs augmented voluntary alcohol intake (Per2SKO versus Per2CTR, $\mathrm{P}<0.01$, ANOVA) and preference (Per2SKO versus Per2CTR, $\mathrm{P}<0.05$, ANOVA) in males (Figures 3D and E), thus mimicking the enhancing effect of striatal Bmall deletion on male alcohol intake and preference. On average, the daily alcohol intake $(15.99 \pm 0.7 \mathrm{~g} / \mathrm{Kg})$ and preference $(0.71 \pm 0.03)$ of Per2SKO male mice was $\sim 33 \%$ higher than intake $(12.01 \pm 1.2 \mathrm{~g} / \mathrm{Kg})$ and preference $(0.53 \pm 0.06)$ in control littermates. In contrast, deletion of Per 2 from MSNs had no effect on alcohol consumption and preference in females (Figures 3F and G), revealing a female-specific dissociation between the effect of Bmall and $\operatorname{Per} 2$ on alcohol intake.

\section{Effect of Deleting a Single Copy of Bmall or Per2 from MSNs on Alcohol Intake}

For a minority of genes, one functional copy is not sufficient to sustain normal function, and mutations causing the loss of function of one of the copies of such gene can impact behavior [57]. To determine if alcohol drinking behavior is affected when only one copy of Bmall is expressed, we assessed alcohol intake and preference in male and female Bmal1HET mice as described above. Although not statistically significant, Bmal1HET males tended to consume and prefer more alcohol than Bmal1CTR male mice (Figure 4A and B). In contrast, Bmal1HET females consumed significantly less alcohol ( $\mathrm{P}<0.02$, ANOVA) and had lower preference $(\mathrm{P}<0.02$, ANOVA) than Bmal1CTR females (Figure 4C and D). These results indicate that the Bmall gene in the MSNs of the striatum is haploinsufficient regarding normal alcohol consumption and preference in females, whereas in males, deletion of one copy of striatal Bmall appears not to affect alcohol intake and preference. Deletion of one copy of Per2 (Per2HET) had no effect on alcohol intake and preference in males or in females, indicating that striatal Per2 is haplosufficient for alcohol intake (Figures 4E, F, G, and H).

Figure 4. Alcohol consumption is altered in Bmall heterozygote female mice

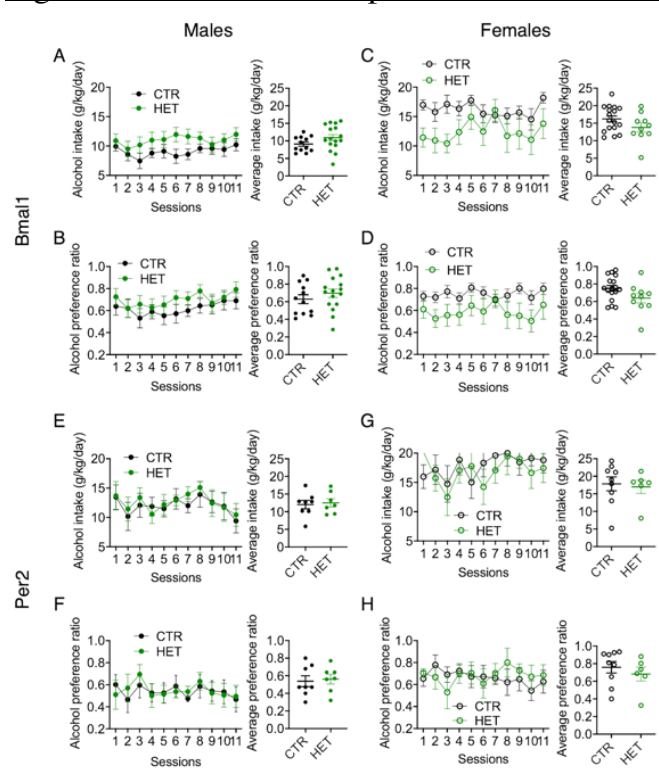

A) Mean \pm S.E.M. of daily alcohol consumption (left) and of average consumption (right) in Bmal1CTR $(n=12)$ and Bmal1HET $(n=16)$ male mice.

B) Mean \pm S.E.M. of daily alcohol preference (left) and of average preference (right) in Bmal1CTR and Bmal1HET male mice C) Mean \pm S.E.M. of daily alcohol consumption (left) and average consumption (right) in Bmal1CTR $(\mathrm{n}=17)$ and Bmal1HET $(\mathrm{n}=10)$ female mice.

D) Mean \pm S.E.M. of daily alcohol preference (left) and average preference (right) in Bmal1CTR and Bmal1HET female mice.

E) Mean \pm S.E.M. of daily alcohol consumption (left) and average consumption (right) in Per2CTR $(n=8)$ and in Per2HET $(n=7)$ male mice.

F) Mean \pm S.E.M. of daily alcohol preference (left) and average preference (right) in Per2CTR $(n=8)$ and in Per2HET $(n=7)$ male mice.

G) Mean \pm S.E.M. of daily alcohol consumption (left) and average consumption (right) in Per2CTR $(n=9)$ and in Per2FET $(n=6)$ female mice.

H) Mean \pm S.E.M. of daily alcohol preference (left) and average preference (right) in Per2CTR and in Per2FET female mice. 


\section{Gpr88 Monoallelic Expression Does Not Affect Alcohol Intake}

Bmal1SKO and Per2SKO mice and their respective HET counterparts have only one functional copy of Gpr88 in MSNs since one copy is modified to drive Cre and GFP expression. Complete deletion of $G p r 88$ has been shown to augment alcohol intake in male mice [58, 59], raising the possibility that the changes in alcohol consumption seen in striatal Bmal1SKO and striatal Per2SKO were due, at least in part, to a sex difference in a contributory effect of Gpr 88 monoallelic expression. To study this possibility, we compared alcohol intake and preference between Gpr88+/+ mice and Gpr88Cre/+ mice. As shown in Supplementary Figure 1A and C, average alcohol intake and preference in $\mathrm{Gpr} 88 \mathrm{Cre} /+$ males were similar to those in $\mathrm{Gpr} 88+/+$ control male mice. Similarly, average alcohol intake and preference in Gpr88Cre/+ females were similar to those in Gpr88+/+ control female mice (Supplementary Figures 1B and D). These results exclude the possibility that the changes in alcohol consumption associated with deletion of striatal Bmall or Per 2 were due to Gpr88 haploinsufficiency, or expression of Cre-EGFP in Gpr88 bearing cells.

\section{Striatal deletion of Bmal1 or Per2 do not affect total fluid intake or sucrose consumption}

Contrary to the effects of Bmall deletion on alcohol intake and preference, deletion of Bmall had no effect on total daily fluid intake across the 11 test sessions in either males or females (supplementary Figures 2A and B). Similarly, in both males and females, deletion of Per2 had no effect on total fluid intake (Supplementary Figures 2C and D). Moreover, striatal deletion of Bmall or Per 2 had no effect on voluntary intake of $0.25 \%$ or $2.0 \%$ sucrose solution (each solution was given in a two-bottle choice with water for 3 consecutive days) in males (Supplementary Figures 2E and G) or females (Supplementary Figures 2F and H). Thus, the effects of striatal deletion of Bmall or Per 2 on alcohol intake and preference in both male and female mice appear not to be the result of global effect on either fluid consumption, general reward processing, or changes in caloric needs.

\section{Striatal deletion of Bmal1 or Per2 Do Not Affect Circadian Wheel-Running Behavior}

Global deletion of Bmall or Per2 or selective deletion from the SCN disrupts circadian behavioral rhythms in animals [5, 60], and disruption of circadian rhythms can influence alcohol consumption [61-63]. To determine whether the effects of Bmall or Per2 deletion in the striatum on alcohol intake and preference was not related to changes in circadian rhythms induced by ectopic Cre recombinase expression, we monitored wheel-running behavior in alcohol naïve mice $(n=7-9$ mice/genotype/sex) housed individually under different lighting conditions. The representative actograms shown in Supplementary Figure 3A show that circadian wheel running rhythms in Bmal1SKO and Bmal1HET male and female mice were indistinguishable from those in respective male and female Bmal1CTR mice. Similarly, wheel running rhythms in Per2SKO and Per2HET male and female mice were indistinguishable from those in respective Per2CTR mice (Supplementary Figure 3B). In particular, Bmall or Per2 deletion did not affect entrainment of daily wheel running to a 12:12 h light-dark cycle, adjustments to phase delay and advance shifts in the light cycle, and free running in constant conditions. These results show that Bmal1SKO and Per2SKO male and female mice and their respective HET mice have a functional SCN molecular clock and normal circadian pacemaking. Thus, the changes in alcohol consumption in SKO and HET male and female mice are independent of the SCN clock and not the result of disrupted circadian behavioral rhythms.

\section{Deletion of Bmal1 or Per2 from MSNs Eliminates Sex Differences in Alcohol Consumption}


Sex differences in alcohol intake and preference are well recognized in animals and humans, with females generally drink more alcohol than males and are at a greater risk of developing alcohol dependence [27-29, 64-66]. Consistent with this, average daily alcohol intake in female Bmal1CTR mice was significantly greater than in Bmal1CTR males $(\mathrm{P}<0.0001$, unpaired twotailed $t$ test) and mean alcohol preference was significantly higher in Bmal1CTR females than Bmal1CTR males $(\mathrm{P}<0.05$, unpaired two-tailed t test), which corresponds to a $78 \%$ greater intake and $21 \%$ higher preference in females, respectively (Supplementary Figure 4A). In contrast, mean alcohol preference in Bmal1SKO male mice was $40 \%$ greater and significantly different compared to Bmal1SKO females ( $\mathrm{P}<0.005$, unpaired two-tailed t test, Supplementary Figure 4C), and no difference was observed in mean alcohol intake between Bmal1SKO males and females (Supplementary Figure 4A). Similarly, average alcohol intake was $46 \%$ greater in Per2CTR females compared to Per2CTR males (intake: $\mathrm{P}<0.001$, unpaired two-tailed t test) and alcohol preference was $40 \%$ higher in Per2CTR females than Per2CTR males (Supplementary Figures 4B and D). In contrast, there were no significant differences in mean alcohol preference and intake between Per2SKO males and females (Supplementary Figures 4B and D). These results show that selective deletion of Bmall from MSNs eliminates sex differences in alcohol intake and preference by augmenting consumption and preference in males and suppressing the heightened intake and preference in females. Likewise, striatal deletion of Per 2 eliminates sex differences in alcohol consumption, although the effect is attributed primarily to augmentation of intake and preference in Bmal1SKO males.

\section{Conclusions}

Polymorphisms in Bmall have been associated with alcohol consumption and alcohol use disorder. Our work reveals, for the first time, a causal role of Bmall in striatal control of alcohol consumption. The influence of striatal Bmall is sexually dimorphic, associated with repression of alcohol preference and intake in male mice, possibly via effect of Per2, and with enhancement of preference and intake in females via a mechanism independent of Per2. Strikingly, while wildtype mice exhibit the well-established heightened female-specific alcohol intake and preference, the opposing effects of Bmall deletion on alcohol intake in males and females abolish this difference. This suggests that sexual dimorphism in the effect of Bmall in the striatum contributes to sex differences in alcohol consumption in mice. The mechanisms that mediate this sexually dimorphic influence are as yet unknown but could involve sex-specific interactions of Bmall with sex hormone receptors and dopamine signaling in MSNs [32, 67-77]. Transcriptomic analysis of differential striatal gene expression in this mouse model could define the downstream outputs of clock gene expression that affect sex differences in alcohol consumption. In summary, our findings uncover a novel Bmall-linked mechanism in striatal MSNs that modulates alcohol intake in a sexually dimorphic manner, and which may contribute to sex differences in alcohol consumption in mice. Whether a similar mechanism in the striatum or elsewhere in the brain contributes to sex differences in other behaviors and disorders remains to be investigated in order to gain better insight into the sexually dimorphic influence of Bmall on behavior.

\section{Supplemental Information}

Supplemental Information includes four figures and Supplemental Experimental Procedures.

\section{Acknowledgments}

This work was funded by grants from the Canadian Institutes of Health Research (S.A). We thank M. Parent, Laval University for the generous gift of tdTomato-D1/GFP-D2 double transgenic mice. 


\section{References}

1. Haque, S.N., Booreddy, S.R., and Welsh, D.K. (2019). Effects of BMAL1 Manipulation on the Brain's Master Circadian Clock and Behavior. Yale J Biol Med 92, 251-258.

2. Lowrey, P.L., and Takahashi, J.S. (2000). Genetics of the mammalian circadian system: Photic entrainment, circadian pacemaker mechanisms, and posttranslational regulation. Annu Rev Genet 34, 533-562.

3. Rijo-Ferreira, F., and Takahashi, J.S. (2019). Genomics of circadian rhythms in health and disease. Genome Med 11, 82.

4. Takahashi, J.S. (2017). Transcriptional architecture of the mammalian circadian clock. Nat Rev Genet 18, 164-179.

5. Bunger, M.K., Wilsbacher, L.D., Moran, S.M., Clendenin, C., Radcliffe, L.A., Hogenesch, J.B., Simon, M.C., Takahashi, J.S., and Bradfield, C.A. (2000). Mop3 is an essential component of the master circadian pacemaker in mammals. Cell 103, 1009-1017.

6. Frederick, A., Goldsmith, J., de Zavalia, N., and Amir, S. (2017). Mapping the colocalization of the circadian proteins PER2 and BMAL1 with enkephalin and substance P throughout the rodent forebrain. PLoS One 12, e0176279.

7. Akladious, A., Azzam, S., Hu, Y., and Feng, P. (2018). Bmal1 knockdown suppresses wake and increases immobility without altering orexin A, corticotrophin-releasing hormone, or glutamate decarboxylase. CNS Neurosci Ther 24, 549-563.

8. Barca-Mayo, O., Pons-Espinal, M., Follert, P., Armirotti, A., Berdondini, L., and De Pietri Tonelli, D. (2017). Astrocyte deletion of Bmal1 alters daily locomotor activity and cognitive functions via GABA signalling. Nat Commun 8, 14336.

9. Yu, X., Zecharia, A., Zhang, Z., Yang, Q., Yustos, R., Jager, P., Vyssotski, A.L., Maywood, E.S., Chesham, J.E., Ma, Y., et al. (2014). Circadian factor BMAL1 in histaminergic neurons regulates sleep architecture. Curr Biol 24, 2838-2844.

10. Hampp, G., Ripperger, J.A., Houben, T., Schmutz, I., Blex, C., Perreau-Lenz, S., Brunk, I., Spanagel, R., Ahnert-Hilger, G., Meijer, J.H., et al. (2008). Regulation of monoamine oxidase A by circadian-clock components implies clock influence on mood. Curr Biol 18, 678-683.

11. Kondratova, A.A., Dubrovsky, Y.V., Antoch, M.P., and Kondratov, R.V. (2010). Circadian clock proteins control adaptation to novel environment and memory formation. Aging (Albany NY) 2, 285-297.

12. Snider, K.H., Dziema, H., Aten, S., Loeser, J., Norona, F.E., Hoyt, K., and Obrietan, K. (2016). Modulation of learning and memory by the targeted deletion of the circadian clock gene Bmal1 in forebrain circuits. Behav Brain Res 308, 222-235.

13. Wardlaw, S.M., Phan, T.X., Saraf, A., Chen, X., and Storm, D.R. (2014). Genetic disruption of the core circadian clock impairs hippocampus-dependent memory. Learn Mem 21, 417-423.

14. Albrecht, U. (2013). Circadian clocks and mood-related behaviors. Handb Exp Pharmacol, 227-239.

15. Schnell, A., Sandrelli, F., Ranc, V., Ripperger, J.A., Brai, E., Alberi, L., Rainer, G., and Albrecht, U. (2015). Mice lacking circadian clock components display different moodrelated behaviors and do not respond uniformly to chronic lithium treatment. Chronobiol Int 32, 1075-1089.

16. Partonen, T. (2015). Clock genes in human alcohol abuse and comorbid conditions. Alcohol 49, 359-365. 
17. Valenzuela, F.J., Vera, J., Venegas, C., Munoz, S., Oyarce, S., Munoz, K., and Lagunas, C. (2016). Evidences of Polymorphism Associated with Circadian System and Risk of Pathologies: A Review of the Literature. Int J Endocrinol 2016, 2746909.

18. Huang, M.C., Ho, C.W., Chen, C.H., Liu, S.C., Chen, C.C., and Leu, S.J. (2010). Reduced expression of circadian clock genes in male alcoholic patients. Alcohol Clin Exp Res 34, 1899-1904.

19. Banach, E., Pawlak, J., Kapelski, P., Szczepankiewicz, A., Rajewska-Rager, A., Skibinska, M., Czerski, P., Twarowska-Hauser, J., and Dmitrzak-Weglarz, M. (2018). Clock genes polymorphisms in male bipolar patients with comorbid alcohol abuse. J Affect Disord 241, 142-146.

20. Kovanen, L., Saarikoski, S.T., Haukka, J., Pirkola, S., Aromaa, A., Lonnqvist, J., and Partonen, T. (2010). Circadian clock gene polymorphisms in alcohol use disorders and alcohol consumption. Alcohol Alcohol 45, 303-311.

21. Chen, G., Cuzon Carlson, V.C., Wang, J., Beck, A., Heinz, A., Ron, D., Lovinger, D.M., and Buck, K.J. (2011). Striatal involvement in human alcoholism and alcohol consumption, and withdrawal in animal models. Alcohol Clin Exp Res 35, 1739-1748.

22. Lu, J., Cheng, Y., Wang, X., Woodson, K., Kemper, C., Disney, E., and Wang, J. (2019). Alcohol intake enhances glutamatergic transmission from D2 receptor-expressing afferents onto D1 receptor-expressing medium spiny neurons in the dorsomedial striatum.

Neuropsychopharmacology 44, 1123-1131.

23. Ma, T., Barbee, B., Wang, X., and Wang, J. (2017). Alcohol induces input-specific aberrant synaptic plasticity in the rat dorsomedial striatum. Neuropharmacology 123, 4654.

24. Roltsch Hellard, E., Binette, A., Zhuang, X., Lu, J., Ma, T., Jones, B., Williams, E., Jayavelu, S., and Wang, J. (2019). Optogenetic control of alcohol-seeking behavior via the dorsomedial striatal circuit. Neuropharmacology 155, 89-97.

25. Wang, J., Cheng, Y., Wang, X., Roltsch Hellard, E., Ma, T., Gil, H., Ben Hamida, S., and Ron, D. (2015). Alcohol Elicits Functional and Structural Plasticity Selectively in Dopamine D1 Receptor-Expressing Neurons of the Dorsomedial Striatum. J Neurosci 35, 11634-11643.

26. Koob, G.F. (2014). Neurocircuitry of alcohol addiction: synthesis from animal models. Handb Clin Neurol 125, 33-54.

27. Ceylan-Isik, A.F., McBride, S.M., and Ren, J. (2010). Sex difference in alcoholism: who is at a greater risk for development of alcoholic complication? Life Sci 87, 133-138.

28. Lancaster, F.E. (1995). Gender differences in animal studies. Implications for the study of human alcoholism. Recent Dev Alcohol 12, 209-215.

29. Sneddon, E.A., White, R.D., and Radke, A.K. (2019). Sex Differences in Binge-Like and Aversion-Resistant Alcohol Drinking in C57BL/6J Mice. Alcohol Clin Exp Res 43, 243249.

30. Peltier, M.R., Verplaetse, T.L., Mineur, Y.S., Petrakis, I.L., Cosgrove, K.P., Picciotto, M.R., and McKee, S.A. (2019). Sex differences in stress-related alcohol use. Neurobiol Stress 10, 100149.

31. Piano, M.R., Carrigan, T.M., and Schwertz, D.W. (2005). Sex differences in ethanol liquid diet consumption in Sprague-Dawley rats. Alcohol 35, 113-118.

32. Cao, J., Willett, J.A., Dorris, D.M., and Meitzen, J. (2018). Sex Differences in Medium Spiny Neuron Excitability and Glutamatergic Synaptic Input: Heterogeneity Across Striatal Regions and Evidence for Estradiol-Dependent Sexual Differentiation. Front Endocrinol (Lausanne) 9, 173. 
33. Wong, J.E., Cao, J., Dorris, D.M., and Meitzen, J. (2016). Genetic sex and the volumes of the caudate-putamen, nucleus accumbens core and shell: original data and a review. Brain Struct Funct 221, 4257-4267.

34. Logrip, M.L., and Gainey, S.C. (2020). Sex differences in the long-term effects of past stress on alcohol self-administration, glucocorticoid sensitivity and phosphodiesterase 10A expression. Neuropharmacology 164, 107857.

35. Kong, L., Chen, K., Womer, F., Jiang, W., Luo, X., Driesen, N., Liu, J., Blumberg, H., Tang, Y., Xu, K., et al. (2013). Sex differences of gray matter morphology in corticolimbic-striatal neural system in major depressive disorder. J Psychiatr Res 47, 733-739.

36. Blanchard, B.A., and Glick, S.D. (1995). Sex differences in mesolimbic dopamine responses to ethanol and relationship to ethanol intake in rats. Recent Dev Alcohol 12, 231241.

37. Lu, Y.F., Jin, T., Xu, Y., Zhang, D., Wu, Q., Zhang, Y.K., and Liu, J. (2013). Sex differences in the circadian variation of cytochrome p450 genes and corresponding nuclear receptors in mouse liver. Chronobiol Int 30, 1135-1143.

38. Lim, A.S., Myers, A.J., Yu, L., Buchman, A.S., Duffy, J.F., De Jager, P.L., and Bennett, D.A. (2013). Sex difference in daily rhythms of clock gene expression in the aged human cerebral cortex. J Biol Rhythms 28, 117-129.

39. Bailey, M., and Silver, R. (2014). Sex differences in circadian timing systems: implications for disease. Front Neuroendocrinol 35, 111-139.

40. Anderson, S.T., and FitzGerald, G.A. (2020). Sexual dimorphism in body clocks. Science $369,1164-1165$.

41. Nicolaides, N.C., and Chrousos, G.P. (2020). Sex differences in circadian endocrine rhythms: Clinical implications. Eur J Neurosci 52, 2575-2585.

42. Kuljis, D.A., Loh, D.H., Truong, D., Vosko, A.M., Ong, M.L., McClusky, R., Arnold, A.P., and Colwell, C.S. (2013). Gonadal- and sex-chromosome-dependent sex differences in the circadian system. Endocrinology 154, 1501-1512.

43. Quintela, T., Sousa, C., Patriarca, F.M., Goncalves, I., and Santos, C.R. (2015). Gender associated circadian oscillations of the clock genes in rat choroid plexus. Brain Struct Funct 220, 1251-1262.

44. Lembach, A., Stahr, A., Ali, A.A.H., Ingenwerth, M., and von Gall, C. (2018). SexDependent Effects of Bmal1-Deficiency on Mouse Cerebral Cortex Infarction in Response to Photothrombotic Stroke. Int J Mol Sci 19.

45. Spanagel, R., Pendyala, G., Abarca, C., Zghoul, T., Sanchis-Segura, C., Magnone, M.C., Lascorz, J., Depner, M., Holzberg, D., Soyka, M., et al. (2005). The clock gene Per2 influences the glutamatergic system and modulates alcohol consumption. Nat Med 11, 3542.

46. Cheng, Y., Huang, C.C.Y., Ma, T., Wei, X., Wang, X., Lu, J., and Wang, J. (2017). Distinct Synaptic Strengthening of the Striatal Direct and Indirect Pathways Drives Alcohol Consumption. Biol Psychiatry 81, 918-929.

47. Ji, X., Saha, S., Kolpakova, J., Guildford, M., Tapper, A.R., and Martin, G.E. (2017). Dopamine Receptors Differentially Control Binge Alcohol Drinking-Mediated Synaptic Plasticity of the Core Nucleus Accumbens Direct and Indirect Pathways. J Neurosci 37, 5463-5474.

48. Peterson, V.L., McCool, B.A., and Hamilton, D.A. (2015). Effects of ethanol exposure and withdrawal on dendritic morphology and spine density in the nucleus accumbens core and shell. Brain Res 1594, 125-135. 
49. Matamales, M., Bertran-Gonzalez, J., Salomon, L., Degos, B., Deniau, J.M., Valjent, E., Herve, D., and Girault, J.A. (2009). Striatal medium-sized spiny neurons: identification by nuclear staining and study of neuronal subpopulations in BAC transgenic mice. PLoS One 4, e4770.

50. Smith, A.D., and Bolam, J.P. (1990). The neural network of the basal ganglia as revealed by the study of synaptic connections of identified neurones. Trends Neurosci 13, 259-265.

51. Chuhma, N., Tanaka, K.F., Hen, R., and Rayport, S. (2011). Functional connectome of the striatal medium spiny neuron. J Neurosci 31, 1183-1192.

52. Gerfen, C.R., Engber, T.M., Mahan, L.C., Susel, Z., Chase, T.N., Monsma, F.J., Jr., and Sibley, D.R. (1990). D1 and D2 dopamine receptor-regulated gene expression of striatonigral and striatopallidal neurons. Science 250, 1429-1432.

53. Van Waes, V., Tseng, K.Y., and Steiner, H. (2011). GPR88 - a putative signaling molecule predominantly expressed in the striatum: Cellular localization and developmental regulation. Basal Ganglia 1, 83-89.

54. Massart, R., Guilloux, J.P., Mignon, V., Sokoloff, P., and Diaz, J. (2009). Striatal GPR88 expression is confined to the whole projection neuron population and is regulated by dopaminergic and glutamatergic afferents. Eur J Neurosci 30, 397-414.

55. Mizushima, K., Miyamoto, Y., Tsukahara, F., Hirai, M., Sakaki, Y., and Ito, T. (2000). A novel G-protein-coupled receptor gene expressed in striatum. Genomics 69, 314-321.

56. Shuen, J.A., Chen, M., Gloss, B., and Calakos, N. (2008). Drd1a-tdTomato BAC transgenic mice for simultaneous visualization of medium spiny neurons in the direct and indirect pathways of the basal ganglia. J Neurosci 28, 2681-2685.

57. Johnson, A.F., Nguyen, H.T., and Veitia, R.A. (2019). Causes and effects of haploinsufficiency. Biol Rev Camb Philos Soc 94, 1774-1785.

58. Ben Hamida, S., Mendonca-Netto, S., Arefin, T.M., Nasseef, M.T., Boulos, L.J., McNicholas, M., Ehrlich, A.T., Clarke, E., Moquin, L., Gratton, A., et al. (2018). Increased Alcohol Seeking in Mice Lacking Gpr88 Involves Dysfunctional Mesocorticolimbic Networks. Biol Psychiatry 84, 202-212.

59. Jin, C., Decker, A.M., Makhijani, V.H., Besheer, J., Darcq, E., Kieffer, B.L., and Maitra, R. (2018). Discovery of a Potent, Selective, and Brain-Penetrant Small Molecule that Activates the Orphan Receptor GPR88 and Reduces Alcohol Intake. J Med Chem 61, 6748-6758.

60. Gavrila, A.M., Robinson, B., Hoy, J., Stewart, J., Bhargava, A., and Amir, S. (2008). Double-stranded RNA-mediated suppression of Period 2 expression in the suprachiasmatic nucleus disrupts circadian locomotor activity in rats. Neuroscience 154, 409-414.

61. Gamsby, J.J., and Gulick, D. (2015). Chronic shifts in the length and phase of the light cycle increase intermittent alcohol drinking in C57BL/6J mice. Front Behav Neurosci 9, 9.

62. Rosenwasser, A.M., and Fixaris, M.C. (2013). Chronobiology of alcohol: studies in C57BL/6J and DBA/2J inbred mice. Physiol Behav 110-111, 140-147.

63. Rosenwasser, A.M., McCulley, W.D., 3rd, Hartmann, M.C., Fixaris, M.C., and Crabbe, J.C. (2020). Suppression of voluntary ethanol intake in mice under constant light and constant darkness. Alcohol 83, 37-46.

64. Darnieder, L.M., Melon, L.C., Do, T., Walton, N.L., Miczek, K.A., and Maguire, J.L. (2019). Female-specific decreases in alcohol binge-like drinking resulting from GABAA receptor delta-subunit knockdown in the VTA. Sci Rep 9, 8102.

65. de la Torre, M.L., Escarabajal, M.D., and Aguero, A. (2015). Sex differences in adult Wistar rats in the voluntary consumption of ethanol after pre-exposure to ethanol-induced flavor avoidance learning. Pharmacol Biochem Behav 137, 7-15. 
66. Plawecki, M.H., White, K., Kosobud, A.E.K., Grahame, N., Zimmermann, U.S., Crabb, D., and O'Connor, S. (2018). Sex Differences in Motivation to Self-Administer Alcohol After 2 Weeks of Abstinence in Young-Adult Heavy Drinkers. Alcohol Clin Exp Res 42, 1897 1908.

67. Chun, L.E., Woodruff, E.R., Morton, S., Hinds, L.R., and Spencer, R.L. (2015). Variations in Phase and Amplitude of Rhythmic Clock Gene Expression across Prefrontal Cortex, Hippocampus, Amygdala, and Hypothalamic Paraventricular and Suprachiasmatic Nuclei of Male and Female Rats. J Biol Rhythms 30, 417-436.

68. Cai, W., Rambaud, J., Teboul, M., Masse, I., Benoit, G., Gustafsson, J.A., Delaunay, F., Laudet, V., and Pongratz, I. (2008). Expression levels of estrogen receptor beta are modulated by components of the molecular clock. Mol Cell Biol 28, 784-793.

69. Zhang, J., Liu, J., Zhu, K., Hong, Y., Sun, Y., Zhao, X., Du, Y., and Chen, Z.J. (2016). Effects of BMAL1-SIRT1-positive cycle on estrogen synthesis in human ovarian granulosa cells: an implicative role of BMAL1 in PCOS. Endocrine 53, 574-584.

70. Almey, A., Milner, T.A., and Brake, W.G. (2015). Estrogen receptors in the central nervous system and their implication for dopamine-dependent cognition in females. Horm Behav 74, 125-138.

71. Almey, A., Milner, T.A., and Brake, W.G. (2016). Estrogen receptor alpha and G-protein coupled estrogen receptor 1 are localized to GABAergic neurons in the dorsal striatum. Neurosci Lett 622, 118-123.

72. Bazzett, T.J., and Becker, J.B. (1994). Sex differences in the rapid and acute effects of estrogen on striatal D2 dopamine receptor binding. Brain Res 637, 163-172.

73. Becker, J.B. (1999). Gender differences in dopaminergic function in striatum and nucleus accumbens. Pharmacol Biochem Behav 64, 803-812.

74. Guivarc'h, D., Vernier, P., and Vincent, J.D. (1995). Sex steroid hormones change the differential distribution of the isoforms of the D2 dopamine receptor messenger RNA in the rat brain. Neuroscience 69, 159-166.

75. Kuppers, E., and Beyer, C. (1998). Expression of aromatase in the embryonic and postnatal mouse striatum. Brain Res Mol Brain Res 63, 184-188.

76. Huber, S.E., Zoicas, I., Reichel, M., Muhle, C., Buttner, C., Ekici, A.B., Eulenburg, V., Lenz, B., Kornhuber, J., and Muller, C.P. (2018). Prenatal androgen receptor activation determines adult alcohol and water drinking in a sex-specific way. Addict Biol 23, 904920 .

77. Mereness, A.L., Murphy, Z.C., and Sellix, M.T. (2015). Developmental programming by androgen affects the circadian timing system in female mice. Biol Reprod 92, 88. 